\title{
Randomized phase II study of daily and alternate-day administration of S-1 for adjuvant chemotherapy in completely- resected stage I non-small cell lung cancer: results of the Setouchi Lung Cancer Group Study 1301
}

Norihito Okumura ${ }^{1 *}$, Junichi Soh ${ }^{2}$, Hiroyuki Suzuki ${ }^{3}$, Masao Nakata $^{4}$, Toshiya Fujiwara ${ }^{5}$, Hiroshige Nakamura ${ }^{6}$, Makoto Sonobe ${ }^{7}$, Takuji Fujinaga ${ }^{8}$, Kazuhiko Kataoka ${ }^{9}$, Kenichi Gemba ${ }^{10}$, Masafumi Kataoka ${ }^{11}$, Katsuyuki Hotta ${ }^{12}$, Hiroshige Yoshioka ${ }^{13}$, Keitaro Matsuo ${ }^{14,15}$, Junichi Sakamoto ${ }^{16}$, Hiroshi Date ${ }^{7}$ and Shinichi Toyooka ${ }^{17}$

\begin{abstract}
Background: The aim of this multicenter, randomized phase II study was to analyze the feasibility and safety of alternate-day S-1, an oral fluoropyrimidine, for adjuvant chemotherapy in patients with completely resected pathological stage I (tumor diameter $>2 \mathrm{~cm}$ ) non-small cell lung cancer (NSCLC).

Methods: Patients were randomly assigned to receive adjuvant chemotherapy for 1 year comprising either alternate-day oral administration of S-1 ( $80 \mathrm{mg} / \mathrm{m}^{2} /$ day) for 4 days a week (Group A) or a 2-week oral administration of S-1 ( $80 \mathrm{mg} / \mathrm{m}^{2} /$ day) followed by 1 week of rest (Group B). The primary endpoint was feasibility, which was defined as the proportion of patients who completed the allocated intervention for 6 months with a relative dose intensity (RDI) of $70 \%$ or more.

Results: Ninety-three patients were enrolled of whom 90 patients received S-1 treatment. Median follow-up was 66.9 months. The treatment completion rate based on an RDI of $70 \%$ or more for 6 months was $84.4 \%(95 \% \mathrm{Cl} ; 70.5-$ 93.5\%) in group A and $64.4 \%(95 \% \mathrm{Cl} ; 48.8-78.1 \%)$ in group B. There were no grade 4 adverse events in either group. Moderate or severe adverse events (grade 2 or grade 3) were significantly more frequent in group B (67\%) compared with group A (29\%, $P=0.001)$. The 5-year relapse-free survival rate was 87.0 and $80.9 \%$ for group $A$ and $\mathrm{B}$, respectively $(P=0.451)$. The 5 -year overall survival rate for all patients $(n=93)$ was 100 and $89.4 \%$ for group $A$ and $B$, respectively $(P=0.136)$.

* Correspondence: no7869@kchnet.or.jp

'Department of Thoracic Surgery, Kurashiki Central Hospital, 1-1-1 Miwa, Kurashiki 710-8602, Japan

Full list of author information is available at the end of the article

(c) The Author(s). 2021 Open Access This article is licensed under a Creative Commons Attribution 4.0 International License, which permits use, sharing, adaptation, distribution and reproduction in any medium or format, as long as you give appropriate credit to the original author(s) and the source, provide a link to the Creative Commons licence, and indicate if changes were made. The images or other third party material in this article are included in the article's Creative Commons licence, unless indicated otherwise in a credit line to the material. If material is not included in the article's Creative Commons licence and your intended use is not permitted by statutory regulation or exceeds the permitted use, you will need to obtain permission directly from the copyright holder. To view a copy of this licence, visit http://creativecommons.org/licenses/by/4.0/ The Creative Commons Public Domain Dedication waiver (http://creativecommons.org/publicdomain/zero/1.0/) applies to the data made available in this article, unless otherwise stated in a credit line to the data. 
(Continued from previous page)

Conclusion: Alternate-day oral administration of S-1 for 1 year as adjuvant chemotherapy was demonstrated to be feasible with low toxicity in completely resected stage I (tumor diameter $>2 \mathrm{~cm}$ ) NSCLC.

Trial registration: Trial registration number: UMIN000011994.

Date of registration: 10/8/2013.

Keywords: Non-small cell lung cancer, Adjuvant chemotherapy, S-1, Alternate-day administration

\section{Background}

Lung cancer is the most common cause of cancerrelated death worldwide [1]. Surgery is considered to be the primary treatment modality for early stage non-small cell lung cancer (NSCLC) and the 5-year overall survival (OS) rates are 88.9 and $76.7 \%$ for pathological stage IA and IB NSCLC patients, respectively [2]. However, 15\% of patients with stage IA NSCLC develop distant metastases even after complete resection [3].

A series of randomized controlled trials, including ANITA, JBR10, and CALGB9633, as well as the LACE meta-analysis, failed to demonstrate an OS benefit of platinum-based chemotherapy following complete surgical resection of pathological N0 NSCLC [4-7].

In Japan, however, a series of randomized phase III trials suggested a survival benefit for adjuvant chemotherapy with the oral drug uracil-tegafur (UFT) in patients with pathological NO NSCLC following complete resection [8-10]. Meta-analysis by Hamada et al. revealed that UFT was beneficial for patients with a tumor size > $2 \mathrm{~cm}$ [11]. On the basis of these findings, the Japanese Lung Cancer Practice Guidelines, which were developed by the Japanese Society of Lung Cancer, recommended UFT therapy in completely resected NO NSCLC patients with a tumor size $>2 \mathrm{~cm}$ for up to 2 years (https://www. haigan.gr.jp/modules/guideline/index.php?content_id=3). Furthermore, a recent randomized phase III trial conducted by our group demonstrated that no survival difference was observed between UFT versus paclitaxel plus carboplatin as adjuvant chemotherapy for completely resected stage IB to IIIB NSCLC [12].

S-1 (TS-1; Taiho Pharmaceutical Co., Ltd., Tokyo, Japan) is an oral fluoropyrimidine agent consisting of tegafur (a prodrug of 5-fluorouracil [5-FU]), gimeracil (an inhibitor of dihydropyrimidine dehydrogenase, which degrades fluorouracil), and oteracil, which inhibits the phosphorylation of fluorouracil in the gastrointestinal tract, thereby reducing the gastrointestinal toxic effects of fluorouracil, in a molar ratio of 1:0.4:1 [13]. S-1 was developed to improve the tumor-selective cytotoxicity of 5-FU, reduce gastrointestinal toxicity, and provide a higher antitumor effect compared with UFT. A phase II trial of S-1 monotherapy as first-line treatment for patients with advanced NSCLC resulted in a $22 \%$ response rate [14]. Regarding the adjuvant setting, S-1 adjuvant chemotherapy following curative surgery improved OS in gastric cancer or pancreatic cancer in phase III trials $[15,16]$. Additionally, in a randomized phase III study, adjuvant chemotherapy with S-1 after curative treatment in patients with head and neck cancer revealed that OS was significantly greater in the S-1 group compared with that in the UFT group [17]. As for NSCLC, some phase II studies for resected NSCLC demonstrated the feasibility and efficacy of S-1 based adjuvant chemotherapy [18-21].

Recently, Kunitoh et al. reported the results of a phase III study that evaluated the efficacy of S-1 compared with UFT for post-operative adjuvant chemotherapy of node negative NSCLC. However, they were unable to demonstrate superiority of adjuvant S-1 therapy over UFT with respect to relapse-free survival (RFS) [22]. They suggested that one reason for the lack of superiority was that the outcomes of patients in the trial were exceedingly good for both arms and that future investigation should incorporate identification of, and be focued on, the high-risk populations for recurrence.

The original schedule for S-1 was a 4 week administration followed by a 2 -week rest period for 1 year (conventional schedule) and the feasibility of administering S-1 according to this conventional schedule has been previously confirmed in patients with completely resected NSCLC [18, 23]. However, the discontinuation or dose reduction of S-1 often occurs because of adverse events during the conventional treatment schedule. To decrease the toxicity of S-1, a modified schedule has been used in which $\mathrm{S}-1$ is administered for 2 weeks followed by a 1week rest period (modified schedule) for patients receiving treatment according to the conventional schedule that experience severe toxicities [24].

A randomized scheduling feasibility study for S-1 has shown that the modified schedule appears to be more feasible compared with the conventional schedule in locoregionally advanced squamous cell carcinoma of the head and neck [25]. In our previous phase II study comparing the conventional and modified schedules of S-1 administration in patients with completely resected pathological stage IA (tumor diameter, $2-3 \mathrm{~cm}$ ) NSCLC, we could not demonstrate a significant difference in feasibility between the two groups. However, we demonstrated that grade $3 / 4$ toxicities were significantly less 
frequent in patients treated with the modified schedule compared with the conventional schedule despite equivalent survival for both groups [26]. As a result, the modified S-1 administration schedule has become more popular in clinical practice.

To further reduce the incidence of drug-induced adverse effects and improve the feasibility of administration, an alternate-day S-1 schedule has recently been investigated. The alternate-day regimen of S-1 was safer and more tolerable compared with the daily regimen in patients with gastric, pancreatic, and head and neck cancer [27-29]. In recent reports, an alternate-day administration of S-1 was also demonstrated to be a potentially safe treatment regimen for elderly patients with advanced NSCLC [30]. To our knowledge, however, there are no reports of prospective studies using an alternateday S-1 administration of adjuvant chemotherapy for completely resected NSCLC.

Therefore, we conducted a multicenter, randomized phase II trial comparing the feasibility and safety of alternate-day administration of S-1 versus daily administration for 2 weeks followed by a 1-week rest period as adjuvant chemotherapy in completely resected stage I (tumor diameter $>2 \mathrm{~cm}$ ) NSCLC.

\section{Methods}

\section{Patients}

Patients who met all the following eligibility criteria and none of the exclusion criteria which are listed in Online Resource 1 were enrolled in this study. The eligibility criteria were as follows: (i) completely resected NSCL $\mathrm{C}$, pathological stage I (according to the Union Internationale Countre le Cancer [UICC] seventh TNM edition) [31] with a tumor diameter $>2 \mathrm{~cm}$, (ii) within 4-6 weeks following surgical resection (lobectomy and larger lung resection) with complete lymph node dissection (ND2a and more extensive in principle), (iii) patients who were able to begin the protocol treatment within 8 weeks after surgical resection, (iv) no prior chemotherapy or radiotherapy, (v) age 20-74 years, (vi) an Eastern Cooperative Oncology Group (ECOG) performance status (PS) of 0 or 1 , (vii) adequate organ function [leukocytes $\geq 3000 / \mu$ l, neutrophils $\geq 1500 / \mu \mathrm{l}$, platelets $\geq 100,000$ / $\mu \mathrm{l}$, hemoglobin $\geq 9.0 \mathrm{~g} / \mathrm{dl}$, total bilirubin $\leq 1.5 \mathrm{mg} / \mathrm{dl}$, aspartate aminotransferase (AST) and alanine aminotransferase (ALT) each $\leq 100 \mathrm{IU} / \mathrm{l}$, creatinine clearance $\geq 40$ $\mathrm{ml} / \mathrm{min}, \mathrm{PaO}_{2} \geq 60 \mathrm{mmHg}$ ] and (viii) written informed consent.

All patients provided written informed consent before enrollment in the study.

\section{Treatment and follow-up}

The randomization was performed centrally at the Department of Preventive Medicine, Kyushu University
Faculty of Medical Sciences, Fukuoka, Japan, with the following stratification factors: institution, histology (squamous cell carcinoma or non-squamous cell carcinoma), pathological stage [stage IA (tumor diameter $>2$ $\mathrm{cm}$ ) or stage IB], and epidermal growth factor (EGFR) mutational status (positive or negative). The patients received S-1 orally twice daily. The dose was $80 \mathrm{mg} /$ body/ day when the body surface area was $<1.25 \mathrm{~m}^{2}, 100 \mathrm{mg} /$ body/day for $1.25-1.50 \mathrm{~m}^{2}$, and $120 \mathrm{mg} /$ body/day for $>$ $1.50 \mathrm{~m}^{2}$. S-1 was randomly administered on alternate days for 4 days (Monday, Wednesday, Friday and Sunday) 1 week (group A) or daily 2 weeks followed by a 1 -week rest period (group B). These cycles were repeated every week (group A) or every 3 weeks (group B) for 1 year after the start of oral administration (Fig. 1). The details of the criteria for discontinuation and restart of S-1 administration, the manner of dose reduction, and the criteria for cessation of the treatment protocol are provided in Online Resource 2, 3, 4 and 5.

As for baseline evaluations, medical history, smoking history, physical examination, operation date, p-TNM status, tumor histology (squamous cell carcinoma or non-squamous cell carcinoma), comorbidity, and laboratory analyses were included. The details of the follow-up assessments are provided in Online Resource 6. Toxicity was graded according to the Common Terminology Criteria for Adverse Events (CTCAE), version 4.0.

\section{Study design and statistical analysis}

The study was designed as a multicenter randomized phase II study, conducted in accordance with the Declaration of Helsinki, and registered with the UMIN Clinical Trial Registry, UMIN000011994. This study adheres to CONSORT guidelines. The study protocol was approved by the institutional review board of each participating institution. All of the study data were managed by the Setouchi Lung Cancer Group (SLCG) 1301 data center at a nonprofit organization, the Epidemiological and Clinical Research Information Network (ECRIN), Kyoto, Japan. The primary endpoint of this study was feasibility, which was defined as the proportion of patients who completed the allocated intervention for 6 months with $70 \%$ or more of relative dose intensity (RDI). RDI was defined as the rate between the actual total administration dose and the planned total administration dose. Treatment completion rates under the conditions described above at 9 months and at 12 months after the initiation of the treatment protocol were also calculated.

This study was designed according to a randomized phase II selection design [32]. We assumed that the threshold 6-month treatment completion rate for the current protocol in both groups was $60 \%$. The decision criteria for the primary endpoint were as follows: 1) If the 6 -month treatment completion rate is $60 \%$ or less in 


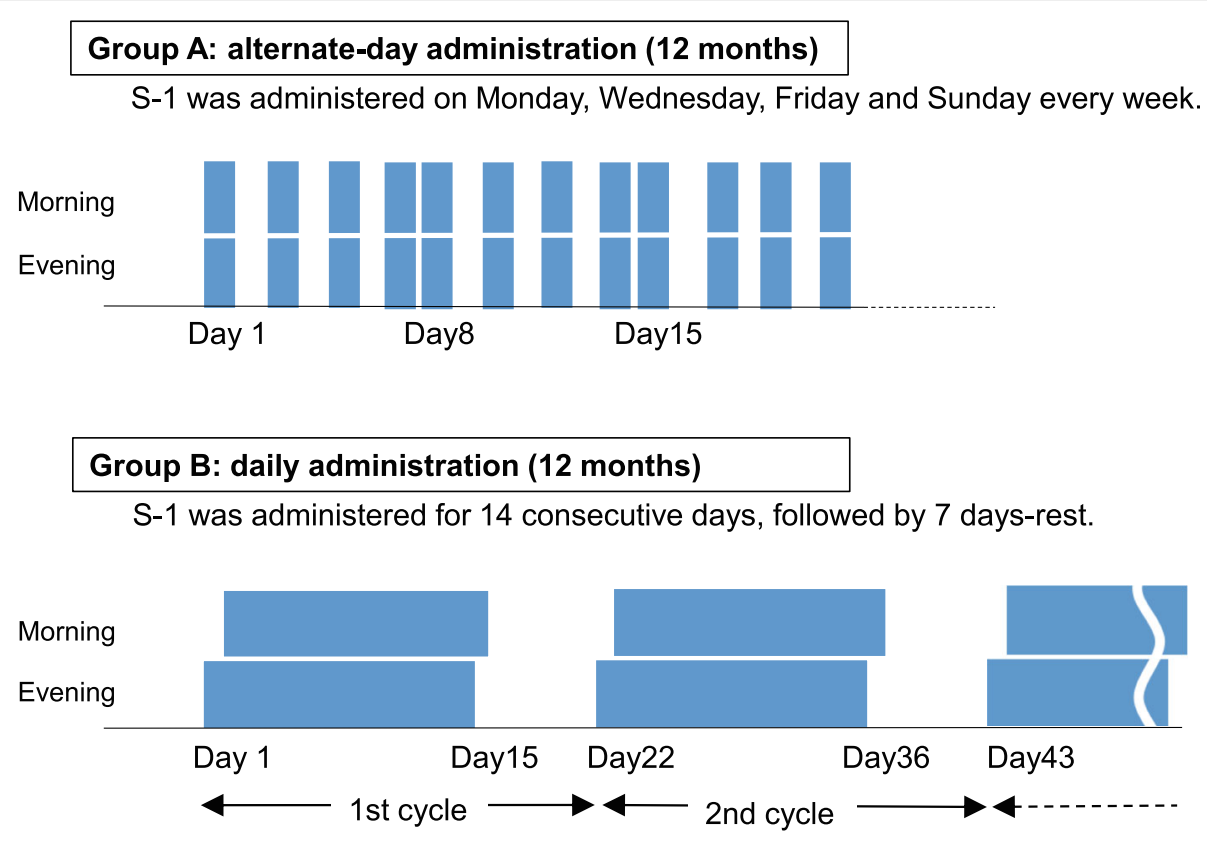

Fig.1 Treatment schedule

Fig. 1 Treatment schedule

both groups, the protocol treatments for both groups is not considered promising. 2) If the 6-month treatment completion rate of one group is more than $60 \%$ and exceeds that of another group by at least $15 \%$, the regimen for the group in which the completion rate was higher is considered promising and selected for further phase III study. 3) If the 6-month treatment completion rate of one group is more than $60 \%$ and exceeds that of another group by $15 \%$ or less, the comparison between the two groups should not be performed with the treatment completion rate. According to the design for assuring 90\% probability for selecting the best study arm, provided that the true expected completion rate exceeded that of another arm by at least $15 \%$, we estimated that the required number of patients would be 37 for each arm. Finally, the sample size was set to 90 considering the potential for patient drop-out because of ineligibility.

The secondary endpoints were toxicity, RFS, and OS. Patients who discontinued the treatment protocol because of tumor recurrence or other complications unrelated to S-1 were treated as censored cases. A final analysis of survival time is expected to be done 5 years after the last enrollment.

Significance differences between the categorized groups were compared using the Fisher's exact test or the Mann-Whitney test. Univariate analysis of OS and RFS was performed using the Kaplan-Meier method with log-rank testing. We defined $P<0.05$ as the threshold for statistical significance. All the statistical analyses were executed using SPSS Statistics ver25 software (IBM, NY, USA).

\section{Results}

\section{Patient characteristics}

Ninety-three patients were enrolled in this trial from 20 institutions in Japan from November 2013 to May 2015. Three patients refused the protocol treatment and 90 patients received allocated intervention (45 in group A and 45 in group B) (Fig. 2). The baseline characteristics of the enrolled patients are summarized in Table 1. Fifty-two patients $(55.9 \%)$ were men and the median age was 67 years old. Eighty-eight $(94.6 \%)$ patients had nonsquamous cell carcinoma histology and $42(45.2 \%)$ patients were pathological Stage IB.

\section{Feasibility}

During the 1-year treatment course, $35.6 \%$ of the patients in group A and $15.6 \%$ of the patients in group B received S-1 administration according to the planned schedule and completed the initial dose without requiring a dose reduction $(P=0.052)$. Treatment discontinuation rates for 1 year were 26.7 and $44.4 \%$ in group A and $\mathrm{B}$, respectively $(P=0.123)$. Treatment was discontinued because of adverse events or toxicity in 5 (11.1\%) and $12(26.7 \%)$ patients in group A and B, respectively $(P=0.104)$. The means of the RDI at 1 year were $78.7 \%$ (SD, 25.6\%) in group A and 59.4\% (SD, 32.1\%) in group B, respectively $(P=0.001)$ (Table 2$)$. 


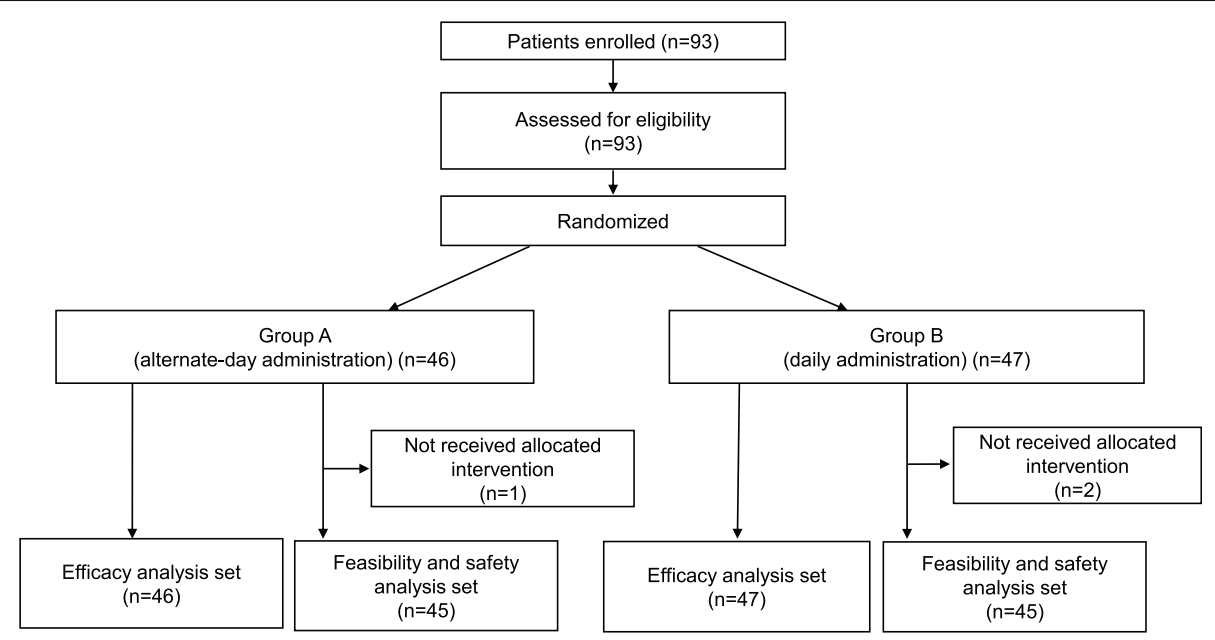

Fig. 2 CONSORT diagram for the current study

Treatment completion rates at 6 months with RDI values more than $70 \%$ were $84.4 \%$ [95\% confidence interval (CI), 70.5-93.5\%] for group $\mathrm{A}$ and $64.4 \%$ (95\%CI, $48.8-78.1 \%)$ for group B $(P=0.052)$. Treatment completion rates at 9 and 12 months in both groups are also shown in Table 3 . The treatment completion rate at 6 months with an RDI value of $70 \%$ or more in group A was greater than $60 \%$ and it exceeded that of group B by more than $15 \%$. According to the established decision criteria, these results indicated that the regimen for group A was promising and it should be selected for a phase III study of adjuvant chemotherapy in completely resected stage I NSCLC.

\section{Toxicity}

A summary of the adverse events is shown in Table 4 . Toxicities were generally well-tolerated in both groups and there were no grade 4 adverse events for any patient. There were also no grade 3 or worse hematological adverse events in either group. The incidence of an adverse event of any grade was 100 and $89 \%$ in group B and A, respectively $(P=0.056)$. Moderate or severe adverse events (grade 2 or grade 3 ) were significantly more frequent in group B (67\%) compared with group A $(29 \%$, $P=0.001$ ). There were no treatment-related deaths in either group during treatment.

The main adverse events were hematological, gastrointestinal, and cutaneous symptoms. Among these,

Table 1 Patient characteristics

\begin{tabular}{|c|c|c|c|c|c|}
\hline Variables & & Total $(n=93)$ & Group $A(n=46)$ & Gropu $B(B=47)$ & $P$ value \\
\hline Age, y & Median (range) & $67(40-74)$ & $67(49-74)$ & $66(40-74)$ & 0.489 \\
\hline \multirow[t]{2}{*}{ Sex } & Male & 52 & 28 & 24 & 0.406 \\
\hline & Female & 41 & 18 & 23 & \\
\hline \multirow[t]{2}{*}{ Smoking } & Present or former smoker & 52 & 28 & 24 & 0.406 \\
\hline & Non-smoker & 41 & 18 & 23 & \\
\hline \multirow[t]{2}{*}{ ECOG PS } & 0 & 79 & 38 & 41 & 0.574 \\
\hline & 1 & 14 & 8 & 6 & \\
\hline \multirow[t]{2}{*}{ Histology } & $\mathrm{Sq}$ & 5 & 2 & 3 & 1.000 \\
\hline & Non-Sq & 88 & 44 & 44 & \\
\hline \multirow[t]{2}{*}{ Pathological stage } & $\mathrm{A}(\mathrm{T}>2 \mathrm{~cm})$ & 51 & 24 & 27 & 0.679 \\
\hline & IB & 42 & 22 & 20 & \\
\hline \multirow[t]{2}{*}{ EGFR-mutation } & Positive & 44 & 21 & 23 & 0.836 \\
\hline & Negative & 49 & 25 & 24 & \\
\hline
\end{tabular}


Table 2 Treatment discontinuation and relative dose intensity

\begin{tabular}{llll}
\hline & Group A $(\boldsymbol{n}=\mathbf{4 5})$ & Group B $(\boldsymbol{n}=\mathbf{4 5})$ & $\boldsymbol{P}$ value \\
\hline $\begin{array}{l}\text { Treatment discontinuation } \\
\text { Reason for discontinuation }\end{array}$ & $12(26.7 \%)$ & $20(44.4 \%)$ & 0.123 \\
$\quad$ Toxicity or adverse event & $5(11.1 \%)$ & $12(26.7 \%)$ & 0.104 \\
Recurrence & $2(4.4 \%)$ & $1(2.2 \%)$ & 1.000 \\
2nd malignancy & $1(2.2 \%)$ & $1(2.2 \%)$ & 1.000 \\
Patient refusal & $3(6.7 \%)$ & $3(6.7 \%)$ & 1.000 \\
Investigator discision & $1(2.2 \%)$ & $2(2.2 \%)$ & 1.000 \\
Others & $0(0 \%)$ & $1(2.2 \%)$ & 1.000 \\
Relative dose intensity at 1 year & & & 0.001 \\
$\quad$ Mean & $78.7 \%$ & $59.4 \%$ & $32.1 \%$ \\
Standard deviation & $25.6 \%$ & & \\
\hline
\end{tabular}

anorexia, skin symptoms, and keratitis/conjunctivitis were more frequent in group B (49, 44 and 16\%,repectively) compared with group A $(20 \% ; P=0.007,11 \%$; $P=0.001$ and $0 \%, P=0.012$, respectively).

\section{Survival}

The median follow-up time was 66.9 months (range, 14.8 to 78.0 months), at which point patients who received the protocol treatment $(n=90)$ and all patients $(n=93)$ had been monitored for at least 5 years. Survival analyses were performed based on an intention to treat. The 5-year RFS rate for all patients $(n=93)$ was 87.0 and $80.9 \%$ for group $\mathrm{A}$ and $\mathrm{B}$, respectively $(P=0.451)$ (Fig. 3). The 5 -year OS rate for all patients $(n=93)$ was 100 and $89.4 \%$ for group $\mathrm{A}$ and $\mathrm{B}$, respectively $(P=$ 0.136) (Fig. 4). Regarding the impact of EGFR gene status on survival, there were no significant differences in OS and RFS between EGFR mutant and wild-type cases among the total population (see Online Resource 7, 8).

\section{Discussion}

The cell cycle period of normal cells is shorter than that of tumor cells (0.5-1 day versus 3-7 days, respectively) and the duration of the $S$-phase in tumor cells is $\geq 1$ day. 5-FU exhibits activity toward S-phase cells by inhibiting DNA synthesis and cell proliferation. Shirasaka et al.

Table 3 Treatment completion rate (Relative dose intensity $\geq$ 70\%)

\begin{tabular}{llll}
\hline & Group A $(\boldsymbol{n}=\mathbf{4 5})$ & Group B $(\boldsymbol{n}=\mathbf{4 5})$ & $\boldsymbol{P}$ value \\
\hline 6 months & $38(84.4 \%)$ & $29(64.4 \%)$ & 0.052 \\
& $(95 \% \mathrm{Cl} ; 70.5-93.5 \%)$ & $(95 \% \mathrm{Cl} ; 48.8-78.1 \%)$ & \\
\multirow{3}{*}{ months } & $34(75.6 \%)$ & $26(57.8 \%)$ & 0.117 \\
& $(95 \% \mathrm{Cl} ; 60.5-87.1 \%)$ & $(95 \% \mathrm{Cl} ; 42.2-72.3 \%)$ & \\
\multirow{3}{*}{12 months } & $31(68.9 \%)$ & $20(44.4 \%)$ & 0.033 \\
& $(95 \% \mathrm{Cl} ; 53.4-81.8 \%)$ & $(95 \% \mathrm{Cl} ; 29.6-60.0 \%)$ & \\
\hline
\end{tabular}

CI Confidence interval recommended the use of an alternate-day schedule for S-1 administration instead of daily use based on the observation that the former would provide time for the recovery of normal epithelial cells in the gastrointestinal tract and bone marrow while still maintaining an anticancer effect [33]. Using gastric cancer cell lines in vitro and in vivo, a previous study showed that alternate-day S-1 administration was associated with lower toxicity while yielding a similar antitumor effect compared with standard daily administration [34]. Moreover, a retrospective study showed that alternate-day S-1 administration was associated with reduced adverse events compared with standard daily S-1 administration in patients with advanced gastric cancer [35]. In a randomized phase II trial for patients with advanced NSCLC, Suzuki et al. demonstrated that the alternate-day administration of S-1 was less toxic and did not compromise its therapeutic effectiveness compared with the standard daily administration of S-1 [36].

In the present study, we compared alternate-day administration of S-1 with daily administration for 2 weeks followed by a 1-week rest in an adjuvant setting for completely resected stage I $(\mathrm{T}>2 \mathrm{~cm})$ NSCLC. In an analysis of a phase III study of postoperative gastric cancer [15], when the protocol completion cases were divided into two groups according to compliance with $\mathrm{S}-1$ administration, the 5-year survival curves overlapped for patients with $\geq 90 \%$ RDI and patients with 70 to $<90 \%$ RDI (in-house experimental data; Taiho Pharmaceutical). Therefore, we concluded that an RDI of $70 \%$ provides sufficient adjuvant chemotherapy for NSCLC with S-1, similar to gastric cancer. A treatment completion rate of 6 months with an RDI of $70 \%$ or more in the alternateday administration group was over 60\% (86.7\%) and exceeded that in the daily administration group by more than $15 \%(22.3 \%)$. On the basis of this result, an alternate-day administration of S-1 appears to be feasible 
Table 4 adverse event

\begin{tabular}{|c|c|c|c|c|c|c|c|c|c|c|c|c|}
\hline \multirow[t]{2}{*}{ Adverse event } & \multicolumn{5}{|c|}{ Group A $(n=45)$} & \multicolumn{5}{|c|}{ Group B $(n=45)$} & \multicolumn{2}{|l|}{$P$ value } \\
\hline & $\overline{\mathrm{G} 1}$ & G2 & G3 & Any grade (\%) & $\overline{\text { G2/G3 (\%) }}$ & $\overline{\mathrm{G} 1}$ & G2 & G3 & Any grade (\%) & G2/G3 (\%) & Any grade & $\overline{G 2 / G 3}$ \\
\hline Any adverse event & 27 & 8 & 5 & $40(89 \%)$ & $13(29 \%)$ & 15 & 24 & 6 & $45(100 \%)$ & $30(67 \%)$ & 0.056 & 0.001 \\
\hline Anemia & 13 & 1 & 0 & $14(31 \%)$ & $1(2 \%)$ & 21 & 2 & 0 & $23(51 \%)$ & $2(4 \%)$ & 0.086 & 1.000 \\
\hline Leukopenia & 7 & 2 & 0 & $9(20 \%)$ & $2(4 \%)$ & 12 & 2 & 0 & $14(31 \%)$ & $2(4 \%)$ & 0.334 & 1.000 \\
\hline Neutropenia & 9 & 1 & 0 & $10(22 \%)$ & $1(2 \%)$ & 7 & 0 & 0 & $7(16 \%)$ & $0(0 \%)$ & 0.591 & 1.000 \\
\hline Thrombocytopenia & 7 & 0 & 0 & $7(16 \%)$ & $0(0 \%)$ & 15 & 0 & 0 & $15(33 \%)$ & $0(0 \%)$ & 0.085 & $* * * *$ \\
\hline Elevation of AST & 12 & 1 & 1 & $14(31 \%)$ & $2(4 \%)$ & 12 & 0 & 0 & $12(27 \%)$ & $0(0 \%)$ & 0.816 & 0.494 \\
\hline Elevation of ALT & 12 & 2 & 0 & $14(31 \%)$ & $2(4 \%)$ & 13 & 1 & 0 & $14(31 \%)$ & $1(2 \%)$ & 1.000 & 1.000 \\
\hline Elevation of LDH & 5 & 0 & 0 & $5(11 \%)$ & $0(0 \%)$ & 10 & 0 & 0 & $10(22 \%)$ & $0(0 \%)$ & 0.258 & $* * * *$ \\
\hline Elevation of bilirubin & 15 & 1 & 0 & $16(36 \%)$ & $1(2 \%)$ & 14 & 6 & 1 & $21(47 \%)$ & $7(16 \%)$ & 0.392 & 0.058 \\
\hline Elevation of creatinine & 3 & 0 & 0 & $3(7 \%)$ & $0(0 \%)$ & 5 & 0 & 0 & $5(11 \%)$ & $0(0 \%)$ & 0.714 & $* * * *$ \\
\hline Anorexia & 8 & 0 & 1 & $9(20 \%)$ & $1(2 \%)$ & 17 & 4 & 1 & $22(49 \%)$ & $5(11 \%)$ & 0.007 & 0.203 \\
\hline Nausea & 12 & 0 & 0 & $12(27 \%)$ & $0(0 \%)$ & 13 & 4 & 0 & $17(38 \%)$ & $4(9 \%)$ & 0.367 & 0.117 \\
\hline Vomiting & 4 & 0 & 0 & $4(9 \%)$ & $0(0 \%)$ & 6 & 1 & 0 & $7(16 \%)$ & $1(2 \%)$ & 0.522 & 1.000 \\
\hline Diarrhea & 5 & 3 & 0 & $8(18 \%)$ & $3(7 \%)$ & 10 & 2 & 1 & $13(29 \%)$ & $3(7 \%)$ & 0.319 & 1.000 \\
\hline Stomatitis & 9 & 0 & 0 & $9(20 \%)$ & $0(0 \%)$ & 9 & 2 & 1 & $12(27 \%)$ & $3(7 \%)$ & 0.619 & 0.242 \\
\hline Fatigue & 4 & 0 & 0 & $4(9 \%)$ & $0(0 \%)$ & 5 & 1 & 0 & $6(13 \%)$ & $1(2 \%)$ & 0.739 & 1.000 \\
\hline Skin symptoms & 4 & 0 & 1 & $5(11 \%)$ & $1(2 \%)$ & 13 & 6 & 1 & $20(44 \%)$ & $7(16 \%)$ & 0.001 & 0.058 \\
\hline Keratinitis/conjunctivitis & 0 & 0 & 0 & $0(0 \%)$ & $0(0 \%)$ & 5 & 2 & 0 & $7(16 \%)$ & $2(4 \%)$ & 0.012 & 0.494 \\
\hline
\end{tabular}

**** incalculable

and promising for adjuvant chemotherapy in completely resected stage I NSCLC.

Toxicities were generally well-tolerated in the current study and there was no grade 4 or worse adverse event in either group. However, moderate or severe adverse events (grade 2 or grade 3 ) were significantly more frequent in the daily administration group (67\%) compared with the alternate-day administration group (29\%, $P=$ 0.001). Moreover, anorexia, skin, and eye symptoms were significantly more frequent in the daily administration group compared with the alternate-day group, indicating that the alternate-day administration may be more tolerable.

In an adjuvant setting, low toxicity is a particularly important factor because postoperative frail patients are likely to be overcome with toxicity and treatment discontinuation resulting from toxicity may attenuate the effectiveness of adjuvant chemotherapy. As a result, alternate-day administration of S-1 would be a good candidate for adjuvant chemotherapy. As for alternate-

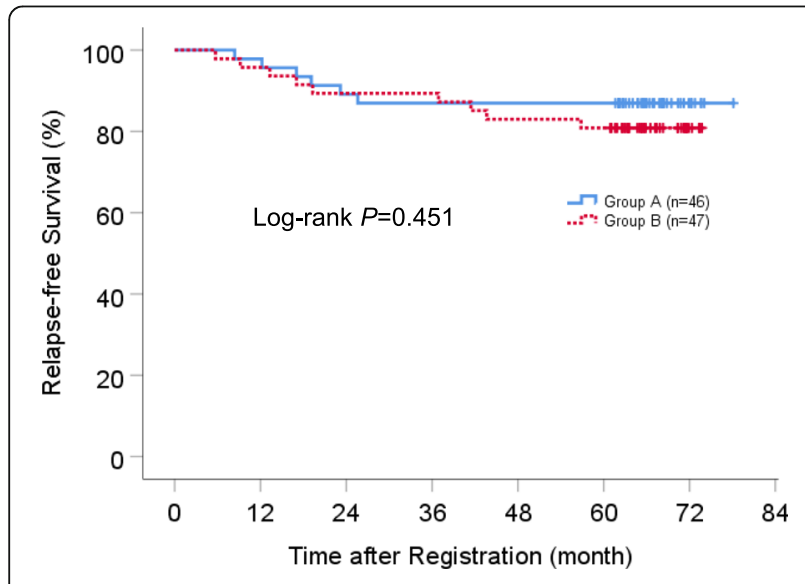

Fig. 3 Kaplan-Meier estimates of relapse-free survival for all patients

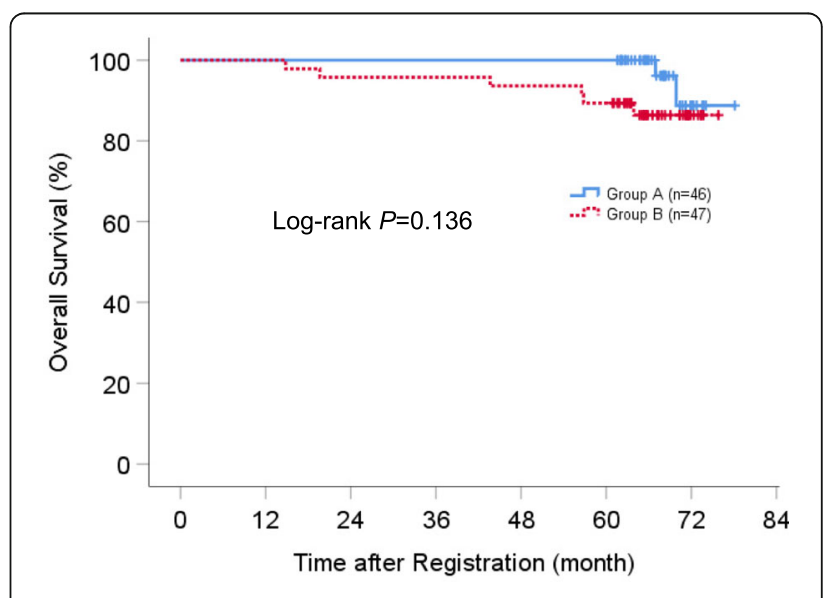

Fig. 4 Kaplan-Meier estimates of overall survival for all patients 
day administration of $\mathrm{S}-1$, fewer studies on adjuvant chemotherapy have been reported compared with that of chemotherapy for advanced cases. Prospective studies of alternate-day S-1 as adjuvant chemotherapy for gastric cancer and head and neck cancer demonstrated improved feasibility, low toxicity, and efficacy $[28,37]$. The current study demonstrated that alternate-day administration of S1 for adjuvant chemotherapy in NSCLC was also feasible and exhibited low toxicity with an acceptable survival rate.

In the phase III study by Kunitoh et al., S-1 was not superior to the efficacy of UFT in the same population as our study. They administered S- 1 daily for 2 weeks followed by a 1 -week rest for 1 year. The dose reduction rate resulting from treatment toxicity was $40.3 \%$ in the S-1 arm compared with $20.1 \%$ in the UFT arm and there were three treatment-related deaths in the S-1 arm [22]. If an alternate-day S-1 administration is adopted, the feasibility and safety of the $\mathrm{S}-1$ arm may be improved while enhancing the effectiveness of the adjuvant chemotherapy. Therefore, our results that demonstrated to be feasible with low-toxicity of alternate-day S-1 administration as adjuvant chemotherapy in resected stage I NSCLC is considered to have a significant clinical implication irrespective of the results of the phase III study by Kunitoh et al.

In addition, the primary endpoint of the Kunitoh study, 5-year RFS, was $79.5 \%$ in the S-1 arm compared with $79.4 \%$ in the UFT arm. The treatment duration was 1 and 2 years in the S-1 and UFT arms, respectively. Considering a similar efficacy for both arms, short duration adjuvant chemotherapy with S-1 may be advantageous compared with UFT therapy.

This study had some limitations. The weaknesses of our study design included the lack of pill counts. Drug compliance may be an important challenge in this study. In addition, information of driver mutation other than EGFR or programmed cell death-ligand 1 (PD-L1) were not collected in this trial. We also did not investigate outcome according to stratification by patient age. A previous study of adjuvant chemotherapy with S-1 according to a conventional daily schedule demonstrated that the RDI of patients over 65 years old was significantly lower compared with that of the other patients. Additionally, the conventional daily administration of S1 was not likely to be feasible in elderly patients with completely resected NSCLC [22]. However, our group is now conducting a randomized phase II trial to confirm the advantage of alternate-day S-1 administration compared with daily S-1 administration as adjuvant chemotherapy for elderly NSCLC patients (UMIN000007819).

\section{Conclusion}

Alternate-day oral administration of S-1 was demonstrated to be feasible with low-toxicity as adjuvant chemotherapy in completely resected stage I (tumor diameter $>2 \mathrm{~cm}$ ) NSCLC. These results are promising and warrant a subsequent phase III study of alternateday administration of S-1 compared with the standard care for these patients, which should be incorporate identification of, and be focued on, the high-risk populations for recurrence according to the results of JCOG0707.

\section{Abbreviations}

NSCLC: Non-small cell lung cancer; RDI: Relative dose intensity; Cl: Confidence interval; SD: Standard deviation; UICC: Union Internationale Countre le Cancer; ECOG: Eastern Cooperative Oncology Group; PS: Performance status; AST: Aspartate aminotransferase; ALT: Alanine aminotransferase; EGFR: Epidermal growth factor; CTCAE: The Common Terminology Criteria for Adverse Events; RFS: Relapse-free survival; OS: Overall survival; DNA: Deoxyribonucleic acid

\section{Supplementary Information}

The online version contains supplementary material available at https://doi. org/10.1186/s12885-021-08232-6.

Additional file 1. Online Resource 1. The exclusion criteria.

Additional file 2. Online Resource 2. The criteria for discontinuation and restant of S-1 administration.

Additional file 3. Online Resource 3. Criteria for dose reduction.

Additional file 4. Online Resource 4. Method for dose reduction of S-1.

Additional file 5. Online Resource 5. The criteria for cessation of the protocol treatment.

Additional file 6. Online resourse 6. Follow-up assessment.

Additional file 7. Online Resource 7. Kaplan-Meier estimates of overall survival.

Additional file 8. Online Resource 8. Kaplan-Meier estimates of relapsefree survival.

\section{Acknowledgements}

We are indebted to Ms. Yumi Miyashita (ECRIN) for data management, Dr. Ayuko Takahashi, Mr. Yoshiharu Yamamoto and Ms. Reiko Moriwake (Kurashiki Central Hospital) for data analysis and Dr. Yoshifumi Sano (Ehime University Hospital), Dr. Hidetoshi Inokawa (Yamaguchi Ube Medical Center), Dr. Nagio Takigawa (Kawasaki Medical School General Medical Center), and Dr. Mitsunori Ishiga (Minami-Okayama Medical Center) for data collection and their contributions to this study.

\section{Authors' contributions}

NO wrote the manuscript; ST, HD and JS1 were responsible for study conception and design; $\mathrm{KH}, \mathrm{HY}$ and $\mathrm{KM}$ prepared the study protocol; $\mathrm{NO}$, JS1, HS, MN, TF, HN, MS, TF, KK, KG and MK collected the data. NO, ST, HD, JS1 and JS2 analyzed and interpreted the data; All co-authors critically revised and approved the paper.

\section{Funding}

No financial support was provided for this study.

\section{Availability of data and materials}

Data and materials of this work are available from the corresponding author on reasonable request.

\section{Declarations}

Ethics approval and consent to participate

The study was approved by Ethics Committee of Okayama University Graduate School of Medicine, Dentistry and Pharmaceutical Sciences and Okayama University Hospital (m12003). Informed consent form was taken from each participant. A confidential ID number was assigned for further 
identification to each participant and to the corresponding data. Both hard and soft copy of the data kept in a safe place; and only principle investigator had access to the data.

\section{Consent for publication}

Not applicable.

\section{Competing interests}

$\mathrm{HD}, \mathrm{ST}, \mathrm{KH}$ and $\mathrm{HY}$ received honoraria from Taiho Pharmaceutical in Japan. All other authors declared no conflicts of interest regarding this study.

\section{Author details}

'Department of Thoracic Surgery, Kurashiki Central Hospital, 1-1-1 Miwa, Kurashiki 710-8602, Japan. ²Department of Surgery, Division of Thoracic Surgery, Kindai University Faculty of Medicine, 377-2 Ohno-Higashi, Osaka-, Sayama, Japan. ${ }^{3}$ Department of Chest Surgery, Fukushima Medical University, 1 Hikarigaoka, Fukushima, Japan. ${ }^{4}$ Department of General Thoracic Surgery, Kawasaki Medical School, 577 Matsushima, Kurashiki, Japan. ${ }^{5}$ Depatment of Thoracic Surgery, Hiroshima City Hiroshima Citizens Hospital, 7-33 Moto-machi, Naka-ku, Hiroshima, Japan. ${ }^{6}$ Division of General Thoracic Surgery, Tottori University Hospital, 36-1, Nishi-cho, Yonago, Japan. ${ }^{7}$ Department of Thoracic Surgery, Kyoto University, 54 Shogoinkawara-cho, Sakyo-ku, Kyoto, Japan. ${ }^{8}$ Department of General Thoracic Surgery, National Hospital Organization Nagara Medical Center, 1300-7 Nagara, Gifu, Japan. ${ }^{9}$ Department of Thoracic Surgery, National Hospital Organization Iwakuni Clinical Center, 1-1-1 Atagomachi, Iwakuni, Japan. ${ }^{10}$ Department of Respiratory Medicine, Chugoku Central Hospital, 148-13 Kamiiwanari, Miyuki-cho, Fukuyama, Japan. ${ }^{11}$ Department of Surgery, Okayama Saiseikai General Hospital, 1-17-18 Ifuku-cho, Kita-ku, Okayama, Japan. ${ }^{12}$ Center for Innovative Clinical Medicine, Okayama University Hospital, 2-5-1 Shikata-cho, Kita-ku, Okayama, Japan. ${ }^{13}$ Department of Thoracic Oncology, Kansai Medical University Hospital, 2-3-1 Shinmachi, Hirakata, Osaka, Japan. ${ }^{14}$ Division of Cancer Epidemiology and Prevention, Aichi Cancer Center Research Institute, 1-1 Kanokoden, Chikusa-ku, Nagoya, Japan. ${ }^{15}$ Department of Preventive Medicine, Kyushu University Faculty of Medical Sciences, 3-1-1 Maidashi, Higashi-ku, Fukuoka, Japan. ${ }^{16}$ Tokai Central Hospital, 4-6-2 Sohara Higashijima-cho, Kakamigahara, Japan. ${ }^{17}$ Department of General Thoracic Surgery and Breast and Endocrinological Surgery, Okayama University Graduate School of Medicine, Dentistry, and Pharmaceutical Science, 2-5-1 Shikata-cho, Kita-ku, Okayama, Japan.

\section{Received: 19 January 2021 Accepted: 21 April 2021}

Published online: 06 May 2021

\section{References}

1. Siegel RL, Miller KD, Jemal A. Cancer statistics, 2019. CA Cancer J Clin. 2019; 69(1):7-34. https://doi.org/10.3322/caac.21551.

2. Okami J, Shintani Y, Okumura M, et al. Demographics, safety and quality, and prognostic information in both the seventh and eighth editions of the TNM classification in 18,973 surgical cases of the Japanese joint committee of lung cancer registry database in 2010. J Thorac Oncol. 2018;14:212-22.

3. Pisters KM, Le Chevalier T. Adjuvant chemotherapy in completely resected non-small-cell lung cancer. J Clin Oncol. 2005;23(14):3270-8. https://doi. org/10.1200/JCO.2005.11.478

4. Douillard JY, Rosell R, De Lena M, et al. Adjuvant vinorelbine plus cisplatin versus observation in patients with completely resected stage IB-IIIA nonsmall-cell lung cancer (adjuvant Navelbine international Trialist association [ANITA]): a randomized controlled trial. Lancet Oncol. 2006;7(9):719-27. https://doi.org/10.1016/S1470-2045(06)70804-X.

5. Butts CA, Ding K, Seymour L, Twumasi-Ankrah P, Graham B, Gandara D, et al. Randomized phase III trial of vinorelbine plus cisplatin compared with observation in completely resected stage IB and II non-small-cell lung cancer: updated survival analysis of JBR-10. J Clin Oncol. 2010;28(1):29-34. https://doi.org/10.1200/JCO.2009.24.0333.

6. Strauss GM, Herndon JE II, Maddaus MA, Johnstone DW, Johnson EA, Harpole DH, et al. Adjuvant paclitaxel plus carboplatin compared with observation in stage IB non-small-cell lung cancer: CALGB 9633 with the cancer and leukemia group B, radiation therapy oncology group, and north central cancer treatment group study groups. J Clin Oncol. 2008;26(31): 5043-51. https://doi.org/10.1200/JCO.2008.16.4855.
7. Pignon JP, Tribodet H, Scagliotti GV, Douillard JY, Shepherd FA, Stephens RJ, et al. Lung adjuvant cisplatin evaluation: a pooled analysis by the LACE collaborative group. J Clin Oncol. 2008;26(21):3552-9. https://doi.org/10.12 00/JCO.2007.13.9030.

8. Wada H, Hitomi S, Teramatsu T, et al. Adjuvant chemotherapy after complete resection in non-small-cell lung cancer. J Clin Oncol. 1996;14(4): 1048-54. https://doi.org/10.1200/JCO.1996.14.4.1048.

9. Nakagawa M, Tanaka F, Tsubota N, Ohta M, Takao M, Wada H, et al. A randomized phase III trial of adjuvant chemotherapy with UFT for completely resected pathological stage I non-small-cell lung cancer: the West Japan study group for lung cancer surgery (WJSG), the 4th study. Ann Oncol. 2005;16(1):75-80. https://doi.org/10.1093/annonc/mdi008.

10. Kato H, Ichinose $\mathrm{Y}$, Ohta M, Hata $\mathrm{E}$, Tsubota $\mathrm{N}$, Tada $\mathrm{H}$, et al. A randomized trial of adjuvant chemotherapy with uracil-tegafur for adenocarcinoma of the lung. N Engl J Med. 2004;350(17):1713-21. https://doi.org/10.1056/ NEJMoa032792.

11. Hamada C, Tanaka F, Ohta M, Fujimura S, Kodama K, Imaizumi M, et al. Meta-analysis of postoperative adjuvant chemotherapy with tegafur-uracil in non-small-cell lung cancer. J Clin Oncol. 2005;23(22):4999-5006. https://doi. org/10.1200/JCO.2005.09.017

12. Toyooka S, Okumura N, Nakamura H, Nakata M, Yamashita M, Tada H, et al. A multicenter randomized controlled study of paclitaxel plus carboplatin versus oral uracil-tegafur as the adjuvant chemotherapy in resected nonsmall cell lung cancer. J Thorac Oncol. 2018;13(5):699-706. https://doi.org/1 0.1016/j.jtho.2018.02.015.

13. Shirasaka T, Nakano K, Takechi T, Satake H, Uchida J, Fujioka A, et al. Antitumor activity of $1 \mathrm{M}$ tegafur-0.4 M 5-chloro-2,4-dihydroxypyridine-1 M potassium oxonate (S-1) against human colon carcinoma orthotopically implanted into nude rats. Cancer Res. 1996;56(11):2602-6.

14. Kawahara M, Furuse $K$, Segawa $Y$, et al. Phase II study of S-1, a novel oral fluorouracil, in advanced non-small-cell lung cancer. Br J Cancer. 2001;85(7): 939-43. https://doi.org/10.1054/bjoc.2001.2031.

15. Sakuramoto S, Sasako M, Yamaguchi T, Kinoshita T, Fujii M, Nashimoto A, et al. Adjuvant chemotherapy for gastric cancer with S-1, an oral fluoropyrimidine. N Engl J Med. 2007;357(18):1810-20. https://doi.org/10.1 056/NEJMoa072252.

16. Uesaka K, Boku N, Fukutomi A, Okamura Y, Konishi M, Matsumoto I, et al. Adjuvant chemotherapy of S-1 versus gemcitabine for resected pancreatic cancer:a phase 3, open-label, randomised non-inferiority trial (JASPAC01). Lancet. 2016;388(10041):248-57. https://doi.org/10.1016/S0140-6736(16)3 0583-9.

17. Tsukahara K, Kubota A, Hasegawa Y, Takemura H, Terada T, Taguchi T, et al. Randomized phase III trial of adjuvant chemotherapy with S-1 after curative treatment in patients with squamous-cell carcinoma of the head and neck (ACTS-HNC). PLoS One. 2015;10(2):e0116965. https://doi.org/10.1371/journal. pone.0116965

18. Tsuchiya T, Nagayasu T, Yamasaki N, Matsumoto K, Miyazaki T, Tagawa T, et al. A multicenter phase II study of adjuvant chemotherapy with oral fluoropyrimidine S-1 for non-small-cell lung cancer: high completion and survival rates. Clin Lung Cancer. 2012;13(6):464-9. https://doi.org/10.1016/j. cllc.2012.01.005.

19. Komazaki Y, Sakashita H, Furuiye M, Fujie T, Tamaoka M, Sumi Y, et al. Feasibility study of adjuvant chemotherapy of S-1 and carboplatin for completely resected non-small cell lung cancer. Chemotherapy. 2013;59(1): 35-41. https://doi.org/10.1159/000351101.

20. Okumura N, Sonobe M, Okabe K, Nakamura H, Kataoka M, Yamashita M, et al. Feasibility of adjuvant chemotherapy with S-1 plus carboplatin followed by single-agent maintenance therapy with S-1 for completely resected non-small-cell lung cancer: results of the Setouchi lung cancer group study 1001. Int J Clin Oncol. 2017;22(2):274-82. https://doi.org/10.1 007/s10147-016-1067-9.

21. Tsuboi M, Kondo K, Takizawa H, Kawakita N, Sawada T, Toba H, et al. A feasibility study of postoperative adjuvant chemotherapy with fluoropyrimidine S-1 in patients with stage II-IIIA non-small cell lung cancer. J Med Investig. 2018;65(1.2):90-5. https://doi.org/10.2152/jmi.65.90.

22. Kunitoh $\mathrm{H}$, Tsuboi M, Wakabayashi M, et al. A phase III study of adjuvant chemotherapy in patients with completely resected, node-negative nonsmall cell lung cancer (JCOG 0707). JTCVS Open. 2020. https://doi.org/10.101 6/j.xjon.2020.08.009.

23. Okumura S, Sasaki T, Satoh K, et al. Feasibility of adjuvant chemotherapy with S-1 consisting of a 4-week administration and a two-week rest period 
in patients with completely resected non-small cell lung cancer. Mol Clin Oncol. 2013;1 (1):124-30. https://doi.org/10.3892/mco.2012.6.

24. Iwasa S, Yamada Y, Fukagawa T, Eguchi Nakajima T, Kato K, Hamaguchi T, et al. Management of adjuvant S-1 therapy after curative resection of gastric cancer: dose reduction and treatment schedule modification. Gastric Cancer. 2011;14(1):28-34. https://doi.org/10.1007/s10120-011-0003-y.

25. Tsukuda M, Kida A, Fujii M, et al. Randomized scheduling feasibility study of S-1 for adjuvant chemotherapy in advanced head and neck cancer. Br J Cancer. 2005;93(8):884-9. https://doi.org/10.1038/sj.bjc.6602804.

26. Soh J, Okumura N, Nakata M, Nakamura H, Fukuda M, Kataoka M, et al. Randomized feasibility study of S-1 for adjuvant chemotherapy in completely resected stage IA non-small-cell lung cancer: results of the Setouchi lung cancer group study 0701. Jpn J Clin Oncol. 2016;46(8):741-7. https://doi.org/10.1093/jjco/hyw062.

27. Arai W, Hosoya $Y$, Hyodo M, Yokoyama T, Hirashima Y, Yasuda Y, et al. Alternate-day oral therapy with TS-1 for advanced gastric cancer. Int J Clin Oncol. 2004;9(3):143-8. https://doi.org/10.1007/s10147-004-0381-9.

28. Yamaue H, Satoi S, Kanbe T, Miyazawa M, Tani M, Kawai M, et al. Phase II clinical study of alternate-day oral therapy with S-1 as first-line chemotherapy for locally advanced and metastatic pancreatic cancer. Cancer Chemother Pharmacol. 2014;73(1):97-102. https://doi.org/10.1007/ s00280-013-2323-6.

29. Moro $Y$, Kogashiwa $Y$, Sato D, et al. Feasibility study of alternate-day $S-1$ as adjuvant chemotherapy for head and neck cancer. Anticancer Res. 2015;35: 977-82.

30. Masuda T, Watanabe M, Fujitaka K, Hamai K, Ishikawa N, Doi M, et al. Alternate-day administration of S-1 for elderly patients with advanced nonsmall-cell lung carcinoma: a prospective feasibility study. Mol Clin Oncol. 2018:9(5):539-44. https://doi.org/10.3892/mco.2018.1705.

31. Sobin LH, Gospodarowicz MK, Wittekind C. TNM classification of malignant tumors. 7th ed. Hoboken: Wiley-Blackwell; 2010.

32. Rubinstein $\mathrm{LV}$, Korn EL, Freidlin $B$, et al. Design issues of randomized phase II trials and a proposal for phase II screening trials. J Clin Oncol. 2005;28: 7199-206.

33. Shirasaka T, Yamamitsu S, Tsuji A, Taguchi T. Conceptual changes in cancer chemotherapy: from an oral fluoropyrimidine prodrug, UFT, to a novel oral fluoropyrimidine prodrug, S-1, and low-dose FP therapy in Japan. Investig New Drugs. 2000;18(4):315-29. https://doi.org/10.1023/A:1006476730671.

34. Arai W, Hosoya Y, Haruta H. Comparison of alternate-day versus consecutive-day treatment with S-1: assessment of tumor growth inhibition and toxicity reduction in gastric cancer cell lines in vitro and in vivo. Int J Clin Oncol. 2008;13(6):515-20. https://doi.org/10.1007/s10147-008-0780-4.

35. Sakuma K, Hosoya Y, Arai W, Haruta H, Ui T, Kurashina K, et al. Alternate-day treatment with S-1 in patients with gastric cancer: a retrospective study of strategies for reducing toxicity. Int J Clin Oncol. 2010;15(2):166-71. https:// doi.org/10.1007/s10147-010-0036-y.

36. Suzuki A, Maemondo M, Sugawara S. Randomized phase II trial of daily administration versus alternate-day administration of S-1 in patients with advanced non-small cell lung cancer. Cancer Treat Res Commun. 2017;12: 56-61. https://doi.org/10.1016/j.ctarc.2017.05.004.

37. Tatebe S, Tsujitani S, Nakamura S, Shimizu T, Yamane N, Nishidoi H, et al. Feasibility study of alternate-day S-1 as adjuvant chemotherapy for gastric cancer: a randomized controlled trial. Gastric Cancer. 2014;17(3):508-13. https://doi.org/10.1007/s10120-013-0289-z.

\section{Publisher's Note}

Springer Nature remains neutral with regard to jurisdictional claims in published maps and institutional affiliations.

Ready to submit your research? Choose BMC and benefit from:

- fast, convenient online submission

- thorough peer review by experienced researchers in your field

- rapid publication on acceptance

- support for research data, including large and complex data types

- gold Open Access which fosters wider collaboration and increased citations

- maximum visibility for your research: over $100 \mathrm{M}$ website views per year

At BMC, research is always in progress.

Learn more biomedcentral.com/submissions 